2008

\title{
A Probabilistic Analysis of The Trading The Line Strategy
}

\author{
V. Abramov \\ KeyBank National Association \\ M. K. Khan \\ KeyBank National Association \\ Rasul A. Khan \\ Cleveland State University, R.KHAN@csuohio.edu
}

Follow this and additional works at: https://engagedscholarship.csuohio.edu/scimath_facpub

Part of the Mathematics Commons

How does access to this work benefit you? Let us know!

\section{Publisher's Statement}

This is an Author's Accepted Manuscript of an article published in Quantitative Finance 2008, available online: http://www.tandfonline.com/10.1080/14697680701489427

\section{Repository Citation}

Abramov, V.; Khan, M. K.; and Khan, Rasul A., "A Probabilistic Analysis of The Trading The Line Strategy" (2008). Mathematics Faculty Publications. 158.

https://engagedscholarship.csuohio.edu/scimath_facpub/158

This Article is brought to you for free and open access by the Mathematics and Statistics Department at EngagedScholarship@CSU. It has been accepted for inclusion in Mathematics Faculty Publications by an authorized administrator of EngagedScholarship@CSU. For more information, please contact library.es@csuohio.edu. 


\title{
A probabilistic analysis of the trading the line strategy
}

\author{
V. ABRAMOV, M. K. KHAN, R. A. KHAN
}

\begin{abstract}
We provide analytic models for which the appropriate statistics of the trading the line strategy, $N_{h}$, can be derived in closed form. In particular, we provide closed form expressions concerning the average duration of the open position, $E\left(N_{h}\right)$, the variance of the open duration, $\operatorname{Var}\left(N_{h}\right)$, the average of the stopped log price, $E\left(S_{N_{h}}\right)$, the variance of the stopped log price, $\operatorname{Var}\left(S_{N_{h}}\right)$, the correlation, $\operatorname{Corr}\left(N_{h}, S_{N_{h}}\right)$, and the Laplace transform, $E\left(\mathrm{e}^{-s N_{h}}\right)$. These results are obtained, in discrete time settings, for binomial and other price scenarios. Furthermore, when analytic results are not possible, such as the case of a normal distribution for $\log$ returns, we show by simulation that our general conclusions still hold. Using these statistics we point out some of the subtle features of the trailing stops strategy.
\end{abstract}

Keywords: Binomial model; Cumulative sum procedure; Financial securities; Geometric random walk; Long position; Short position; SPRT; Trailing stops strategy; Trinomial model

\section{Introduction}

When one enters into a long (short) investment position, the expectation is that the value of the asset will rise (fall). After making the entry decision, the most critical decision eals with the setting of an exit position. When the possession of exact future information is ruled out, it will be difficult to scientifically justify the optimality of any emotionally derived exit decision. Various trading strategies, such as 'stop loss' and the 'trading the line' (also called 'trailing stops') strategy, have been devised to minimize losses (or lock in profits), if the market suddenly moves against an open position (Markese 1990, Glynn and Iglehart 1995, Eng 1996, Acar and Satchell 2002, Jenks and Eckett 2002, Cofnas 2004). Although the literature on the use of the trailing stops strategy is voluminous, comparatively little is available in terms of its theoretical properties and analysis. This is partly due to the fact that the mathematical models quickly become intractable, even in the simplest price scenarios. In discrete time settings, among the few exceptions are the studies of Iglehart and Stone (1983) and Glynn and Iglehart (1995), where the trailing stops strategy is analysed for two types of models for the underlying security, and Shen and Wang (2001), where the stop-loss strategy is studied.

One of the aims of this paper is to provide a probabilistic framework by which an analytic analysis can be performed for the trailing stops strategy under various price dynamics. This, in part, is done by making a connection to the cumulative sum (cusum) procedure of quality control. Although the cusum procedure has been studied quite extensively (Dobben de Bruy 1968, Khan 1979, 1984), its link with the trailing stops strategy has mostly been untapped. The recent article of Khan and Khan (2004) provides some theoretical results that can be used to derive fundamental properties, in closed form, for the trailing stops strategy under various price dynamics for both long and short positions.

Glynn and Iglehart (1995) studied the trailing stops strategy when the price process is a geometric random walk generated by binomial or double exponential random variables, in the discrete case, and for geometric Brownian motion for the continuous case. In this strategy for the long position, one sets an amount, $h$, by which the log price needs to fall, compared with the past maximum, to trigger immediate selling of the investment. Should the price rise above the historic maximum, the new maximum becomes the current benchmark. There are several issues 
that require analysis. Among the basic issues are the following.

- The expected trading duration, once one enters into a short (long) position, called the expected first passage time, or average run length of the strategy. Symbolically, if $N_{h}$ is the duration of the short position of the trailing stop strategy, obtain its expected duration, $E\left(N_{h}\right)$.

- The variance of the trading duration of the strategy, $\operatorname{Var}\left(N_{h}\right)$.

- The expected level of the price at the exit time, called the stopped value, i.e. $E\left(S_{N_{h}}\right)$.

- The variance of the stopped value, $\operatorname{Var}\left(S_{N_{h}}\right)$.

- The correlation between the stopped amount and the duration of the trading strategy, $\operatorname{Corr}\left(N_{h}, S_{N_{h}}\right)$.

- The sensitivity of the above parameters to the trailing stops triggering level, $h$.

- The sensitivity of the above parameters to the various price dynamics.

Several criteria for the choice of the triggering constant, $h$, are presented, for instance, by Glynn and Iglehart (1995), therefore we will not consider this aspect of the strategy in this paper. Historically, continuous time settings have been used to study the properties of stopping times along with the stopped processes, and the results are often implicit in terms of the solutions of ordinary differential equations (Darling and Siegert 1953). The second aim of the paper is to show that discrete time analysis, in contrast to continuous time analysis, can provide exact and tractable closed-form solutions, at least for certain types of price dynamics, which we specify in the paper.

In the next section we provide an analytic analysis of the trailing stops strategy under various price processes. We provide an exact correlation formula between the stopping time and the stopped amount. The formula depends on the expected stopping time and the variance of the stopping time. In particular, we are able to provide the average run length and the variance of the stopping time in closed form for some price dynamics, such as the binomial, trinomial, geometric and exponential models where the inter-observation duration could be chosen to be as small as practically possible. We should also point out that, for log normal processes, a closed-form expression for the expected stopping time is still an open problem. In section 3, specific price scenarios are analysed. The last section summarizes the results.

\section{Analysis of the trading the line strategy}

Let $Y_{1}, Y_{2}, \ldots$, be independent and identically distributed random variables representing the returns of the underlying security. Throughout we will assume that $0<\operatorname{Var}\left(Y_{1}\right)<\infty$. The random variables $Y_{i}$ can be discrete or continuous. Let $S_{n}=Y_{1}+\cdots+Y_{n}$, and let $P_{n}=P_{0} \mathrm{e}^{S_{n}}$, $n \geq 1$, be the price process, where $P_{0}$ is a constant. The trading the line strategy can be defined in several ways. For instance, using the log of the price process, $S_{n}$, for the long position, we may define the stopping rule

$$
L_{h}:=\inf \left\{n \geq 1: \max _{k \leq n} S_{k}-S_{n} \geq h\right\},
$$

where $h>0$ is the specified amount by which the log price has to drop to trigger sellout. The corresponding trailing stops strategy for the short position is

$$
N_{h}:=\inf \left\{n \geq 1: S_{n}-\min _{k \leq n} S_{k} \geq h\right\},
$$

where $h>0$ is the specified amount by which the log price has to rise to trigger closing the position. Of course, the triggering constant, $h$, need not be the same for the two strategies.

Instead of using the log-price process, one may use the price process itself, $P_{n}=P_{0} \exp \left(S_{n}\right)$, to define another stopping rule:

$$
T_{h}:=\inf \left\{n \geq 1: \max _{k \leq n} P_{k}-P_{n} \geq h\right\} .
$$

Let us denote $M_{n}=\max _{k \leq n} S_{n}$. Then we can rewrite

$$
\max _{k \leq n} P_{k}-P_{n} \geq h
$$

as

$$
P_{0} \mathrm{e}^{M_{n}}-P_{0} \mathrm{e}^{S_{n}} \geq h .
$$

Divide both sides by $P_{0} \mathrm{e}^{M_{n}}$ and simplifying gives

$$
\left.M_{n}-S_{n} \geq \log \left[\frac{P_{0} \mathrm{e}^{M_{n}}-h}{P_{0} \mathrm{e}^{M_{n}}}\right]^{1}\right) \text {. }
$$

Using the fact that $P_{0} \mathrm{e}^{M_{n}}=\max _{k \leq n} P_{k}$ and simplifying we finally obtain

$$
M_{n}-S_{n} \geq \log \left(\frac{\max _{k \leq n} P_{k}}{\max _{k \leq n} P_{k}-h}\right) .
$$

Therefore, we can rewrite the stopping time $T_{h}$ in the following equivalent form:

$$
T_{h}:=\inf \left\{n \geq 1: \max _{k \leq n} S_{k}-S_{n} \geq \Lambda_{n}\right\},
$$

where $\Lambda_{n}=\log \left(\max _{k \leq n} P_{k} /\left(\max _{k \leq n} P_{k}-h\right)\right)$. Although this form resembles $L_{h}$, since $\Lambda_{n}$ is random, mathematically it leads to a different and less-tractable problem. For this reason, our main focus will be on the stopping rules $L_{h}$ and $N_{h}$, which are analytically more tractable. Furthermore, due to the fact that the stopping rules $N_{h}$ and $L_{h}$ are related, one does not need to study both separately. Indeed, by taking $Z_{i}=-Y_{i}$ in $N_{h}$ we obtain the stopping rule $L_{h}$. Hence, throughout, our primary focus will be on deriving results for $N_{h}$ only. The corresponding results for $L_{h}$ can be deduced by the transformation $Z_{i}=-Y_{i}$.

For the sake of comparison, we start by considering a trading strategy, $v$, that is independent of the log-price process, $\left\{S_{n}, n \geq 0\right\}$. The following result shows how the 
correlation of $S_{v}$ and $v$ is dependent on the basic statistics of the stopping rule.

Proposition 2.1: Let $Y_{1}, Y_{2}, \ldots$ be any sequence of independent and identically distributed random variables with $E\left(Y_{1}^{2}\right)<\infty$. If $v$ is any stopping rule independent of the log return process, $Y_{1}, Y_{2}, \ldots$, having positive finite variance, and $S_{n}=Y_{1}+\cdots+Y_{n}$, then the correlation between $v$ and $S_{v}$ is

$$
\operatorname{Corr}\left(v, S_{v}\right)=\frac{E\left(Y_{1}\right)}{\sqrt{E\left(Y_{1}^{2}\right)+\operatorname{Var}\left(Y_{1}\right) E(v) / \operatorname{Var}(v)}} .
$$

The proof of this and the following proposition can be deduced by Wald's equation or the theorem of total expectation (Billingsley 1979). We omit the simple details.

Proposition 2.2: Let $P_{n}, n \geq 1$, be the price process governed by a geometric random walk, $P_{n}=P_{0} \mathrm{e}^{S_{n}}$, where $S_{n}=Y_{1}+\cdots+Y_{n}$, and let $Y_{1}, Y_{2}, \ldots$ be a sequence of independent and identically distributed random variables with moment generating function $\phi(\theta)=E\left(\mathrm{e}^{\theta Y_{1}}\right)$. If $v$ is any trading strategy that is independent of the log return process, $Y_{1}, Y_{2}, \ldots$, then the mean and the variance of the time discounted gain/loss are as follows:

$$
\begin{aligned}
E\left(P_{0}-e^{r v} P_{\nu}\right) & =P_{0}\left(1-E\left(e^{(r s) v}\right)\right), \\
\operatorname{Var}\left(P_{0}-e^{r v} P_{v}\right) & =P_{0}^{2}\left\{E\left(e^{(2 r \alpha) v}\right)-\left(E\left(e^{(r s) v}\right)\right)^{2}\right\},
\end{aligned}
$$

where $s=\ln \phi(1), \alpha=\ln \phi(2)$ and $r$ is the discounting rate.

The above two propositions show that the key statistics are $E(v), \operatorname{Var}(v)$ and the Laplace transform $E\left(\mathrm{e}^{-s v}\right)$. The aim of this paper is to consider the trading strategy, $N_{h}$, which is adapted to the filtration $\mathcal{F}_{n}=\sigma\left(Y_{1}, Y_{2}, \ldots, Y_{n}\right)$, $n \geq 1$. In other words, the decision to stop at time $n$ is purely determined by the information available up to time $n$, and not any information that would come in the future. Once again, the key statistics that are needed are the average amount of time the position will remain open, $E\left(N_{h}\right)$, the variance of the time the position will remain open, $\operatorname{Var}\left(N_{h}\right)$, and the Laplace transform $E\left(\mathrm{e}^{-s N_{h}}\right)$, for appropriate values of $s$. In order to study the properties of the short position trailing stops, $N_{h}$, the corresponding stopped $\log$ price, $S_{N_{l}}$, and the time discounted gain/loss $P_{0}-\mathrm{e}^{-r N_{h}} P_{N_{h}}$, the following proposition explains how a double boundary crossing stopping rule, called the SPRT, plays an important role,

$$
\tau_{a, h}:=\inf \left\{n \geq 1: S_{n} \notin(a, h)\right\},
$$

where $a<0<h$. The following result concerning $\tau_{a, h}$ is from Khan and Khan (2004).

Proposition 2.3: The stopping rules $N_{h}$ and $\tau_{0, h}$ are related through the identity

$$
N_{h}=\tau_{0, h}+N_{h, \tau_{0, h}} I\left(S_{\tau_{0, h}} \leq 0\right),
$$

where $N_{h, \tau_{0, h}}$ is an identical copy of $N_{h}$ that is independent of $S_{\tau_{0, h}}$ when $\tau_{0, h}$ is given. Here and elsewhere, $I(A)$ is the indicator random variable taking value 1 when $A$ occurs and 0 otherwise.
With the help of this link we easily deduce the Laplace transform of $N_{h}$ in terms of the Laplace transform of the SPRT. Therefore, the statistics of $N_{h}$ are, in turn, linked to the statistics of the SPRT.

Proposition 2.4: For any $s>0$, we have

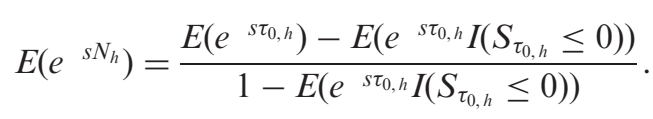

The above Laplace transform of $N_{h}$ and its relationship to $\tau_{0, h}$ has been known in the quality control literature for some time. The main stumbling block has been the calculation of the expressions on the right-hand side. The recent paper of Khan and Khan (2004) provides a mechanism by which to compute the above expressions, in a closed form, under the following assumptions.

- (A1) The moment generating function of $\log$ returns, $\phi(\theta)=E\left(\mathrm{e}^{\theta Y_{i}}\right)$, exists.

- (A2) For each small $s>0$, there exist two values of $\theta$, say $\theta_{1}(s), \theta_{2}(s)$, so that $\phi(\theta)=\mathrm{e}^{s}$ holds for $\theta=\theta_{1}(s), \theta_{2}(s)$.

- (A3) There exist functions $K(\theta), k(x), R(\theta), g(x)$, so that, for $\theta=0, \theta_{1}, \theta_{2}$,

$$
\begin{array}{ll}
H(x):=E\left(\mathrm{e}^{\theta Y_{1}} I\left(Y_{1} \leq x\right)\right)=K(\theta) k(x) \mathrm{e}^{\theta x}, & x<0, \\
G(x):=E\left(\mathrm{e}^{\theta Y_{1}} I\left(Y_{1} \geq x\right)\right)=R(\theta) g(x) \mathrm{e}^{\theta x}, & x>0 .
\end{array}
$$

Here, in the notation $H(x), G(x)$, we suppress the dependence on $\theta$ and $s$.

As examples, the binomial, trinomial, two-sided geometric and double exponential models for the log returns obey the above sets of conditions. Under the above assumptions, the following two theorems are the main results that give the probabilistic properties of the trailing stops strategy for the short position. Analogous results can be obtained, by replacing $Y_{i}$ with $-Y_{i}$, for the trailing stops strategy in the long position; we therefore omit the straightforward details.

Theorem 2.5 (non-degenerate case): Under the above assumptions, when $K(\theta), R(\theta)$ are not constant functions (non-degenerate case), the short position trailing stops strategy, $N=N_{h}$, has the following Laplace transform, mean and variance:

$$
\begin{array}{cl}
E\left(e^{-s N}\right) \quad & \frac{R(0)\left\{K\left(\theta_{1}\right)-K\left(\theta_{2}\right)\right\}}{\left\{K\left(\theta_{1}\right)-K(0)\right\} R\left(\theta_{2}\right) e^{\theta_{2} h}-\left\{K\left(\theta_{2}\right)-K(0)\right\} R\left(\theta_{1}\right) e^{\theta_{1} h},} \\
& s>0, \\
E(N) & \frac{1}{E(Y)}\left\{h+\frac{R^{\prime}(0)}{R(0)}-\frac{K^{\prime}(0)\left\{R(0)-R\left(\theta^{*}\right) e^{\theta^{*} h}\right\}}{R(0)\left(K(0)-K\left(\theta^{*}\right)\right)}\right\}, \\
E(Y) & / 0,
\end{array}
$$

where $\theta_{1}(s) \rightarrow 0$ and $\theta_{2}(s) \rightarrow \theta *$ as $s \rightarrow 0$. When $E(Y)=0$, we obtain

$$
\begin{aligned}
E(N)= & \frac{1}{\operatorname{Var}(Y)}\left\{h^{2}+h \frac{2 R^{\prime}(0) K^{\prime}(0)-R(0) K^{\prime \prime}(0)}{R(0) K^{\prime}(0)}\right. \\
& \left.+\frac{K^{\prime}(0) R^{\prime \prime}(0)-R^{\prime}(0) K^{\prime \prime}(0)}{R(0) K^{\prime}(0)}\right\} .
\end{aligned}
$$


Furthermore, when $\theta_{1}^{\prime}(s)+\theta_{2}^{\prime}(s)=0$ in the neighbourhood of zero, and $E(Y) \neq 0$, the variance simplifies to

$$
\begin{aligned}
\operatorname{Var}(N)= & \frac{1}{(E(Y))^{2}}\{\operatorname{Var}(Y) E(N)+2(E(Y) E(N)-h) \\
& \times \frac{K^{\prime}(0)+K^{\prime}\left(\theta^{*}\right)}{K(0)-K\left(\theta^{*}\right)}+(E(Y) E(N)-h)^{2} \\
& +\frac{K^{\prime \prime}(0)\left\{R(0)-R\left(\theta^{*}\right) e^{\theta^{*} h}\right\}}{R(0)\left(K(0)-K\left(\theta^{*}\right)\right)}-\frac{R^{\prime \prime}(0)}{R(0)} \\
& -2 \frac{K^{\prime}\left(\theta^{*}\right) R^{\prime}(0)-K^{\prime}(0) R^{\prime}\left(\theta^{*}\right) e^{\theta^{*} h}}{R(0)\left(K(0)-K\left(\theta^{*}\right)\right)} \\
& \left.+4 h \frac{K^{\prime}(0) R\left(\theta^{*}\right) e^{\theta^{*} h}}{R(0)\left(K(0)-K\left(\theta^{*}\right)\right)}\right\} .
\end{aligned}
$$

Theorem 2.6 (degenerate case): When $Y$ is an integer valued random variable and $K(\theta), R(\theta)$ are constants, the trailing stops strategy for the short position, $N=N_{h}$, has the following Laplace transform, mean and variance:

$$
\begin{aligned}
E\left(e^{s N}\right) & =\frac{e^{\theta_{2}}-e^{\theta_{1}}}{\left(1-e^{\theta_{1}}\right) e^{\theta_{2}(h+1)}-\left(1-e^{\theta_{2}}\right) e^{\theta_{1}(h+1)}}, \quad s>0, \\
E(N) & =\frac{1}{E(Y)}\left\{h+\frac{1-e^{\theta^{*} h}}{1-e^{\theta^{*}}}\right\}, \quad E(Y) \neq 0, \\
E(N) & =\frac{h(h+1)}{\operatorname{Var}(Y)}, \quad E(Y)=0 .
\end{aligned}
$$

Furthermore, when $\theta_{1}^{\prime}(s)+\theta_{2}^{\prime}(s)=0$ in the neighbourhood of zero, where $\theta_{1}(s) \rightarrow 0$ and $\theta_{2}(s) \rightarrow \theta^{*}$ as $s \rightarrow 0$, and $E(Y) \neq 0$, the variance simplifies to

$$
\begin{aligned}
\operatorname{Var}(N)= & \frac{\operatorname{Var}(Y)}{(E(Y))^{3}}\left\{h+\frac{1-e^{\theta^{*} h}}{1-e^{\theta^{*}}}\right\} \\
& +\frac{\left\{e^{\theta^{*}(h+1)}+3\right\}\left\{e^{\theta^{*} h}-1\right\}}{(E(Y))^{2}\left(1-e^{\theta^{*}}\right)\left(e^{\theta^{*}}-1\right)}+\frac{4 h e^{\theta^{*}(h+1)}}{(E(Y))^{2}\left(1-e^{\theta^{*}}\right)} .
\end{aligned}
$$

We should point out that the last term of the expression for $\operatorname{Var}(N)$ in Khan and Khan (2004) has a minor typographical error, where $1-(2 h+1) \mathrm{e}^{\theta *(h+1)}$ should be replaced by $-2 h \mathrm{e}^{\theta *(h+1)}$. Using these results, we can compute the exact expressions for the various statistics of the duration of the open position, $N_{h}$, and the stopped log price, $S_{N_{h}}$. The following proposition gives the correlation.

Proposition 2.7: Let $Y_{1}, Y_{2}, \ldots$ be any sequence of independent and identically distributed random variables with $0<E\left(Y_{1}^{2}\right)<\infty, E\left(Y_{1}\right) \neq 0$, and let $S_{n}=Y_{1}+\cdots+Y_{n}$. If $v$ is any stopping rule adapted to the filtration $\sigma\left(Y_{1}, Y_{2}, \ldots, Y_{n}\right), n \geq 1$, having finite positive variance, then

$$
\operatorname{Corr}\left(v, S_{v}\right)=\frac{\operatorname{Var}\left(S_{v}\right)+\left(E\left(Y_{1}\right)\right)^{2} \operatorname{Var}(v)-\operatorname{Var}\left(Y_{1}\right) E(v)}{2 E\left(Y_{1}\right) \sqrt{ } \operatorname{Var}(v) \operatorname{Var}\left(S_{v}\right)} .
$$

Proof: Let $\mu=E\left(Y_{1}\right)$ and $\sigma^{2}=\operatorname{Var}\left(Y_{1}\right)$. Wald's equation applied to the martingale $\left(S_{n}-n \mu\right)^{2}-n \sigma^{2}$ gives

$$
E\left(\nu S_{\nu}\right)=\frac{1}{2 \mu}\left(E\left(S_{v}^{2}\right)+\mu^{2} E\left(v^{2}\right)-\sigma^{2} E(v)\right) .
$$

Using these results gives the desired expression for the correlation.

In the next section we illustrate the above results using several examples.

\section{Trailing stop strategy for various price dynamics}

In this section we provide some results under various price scenarios for the log return process. Only in the first two examples are we able to obtain $\operatorname{Var}\left(S_{N_{h}}\right)$ when $E\left(Y_{1}\right) \neq 0$. Therefore, by proposition 2.7, for these two examples we are able to find closed-form expressions for $\operatorname{Corr}\left(N_{h}, S_{N_{h}}\right)$. When $\mu=E\left(Y_{1}\right)=0$, since $S_{n}^{2}-n \sigma^{2}$ is a martingale, we have $\operatorname{Var}\left(S_{N_{h}}\right)=E\left(S_{N_{h}}^{2}\right)=\sigma^{2} E\left(N_{h}\right)$. In all the examples presented in this section, $\operatorname{Var}\left(S_{N_{h}}\right)$ is computed this way whenever $E\left(Y_{1}\right)=0$. It should be noted that when $Y_{i}$ are integer valued random variables, the constant $h>0$ need only take positive integer values. This is because the stopping rule does not change if the noninteger value of $h$ is replaced by the least integer greater than or equal to $h$.

Example 3.1 (binomial model): Consider the typical binomial model in which the log returns, $Y_{i}$, can take two possible values, $-1,1$, with respective probabilities $q$, $p=1-q$. In this example we can obtain exact results. Cox et al. (1979) used the binomial model to give a simplified approach to pricing options. Later, Glynn and Iglehart (1995) studied this model in the context of a long position of the trailing stops strategy with positive drift, $E(Y)=p-q>0$. They computed $E\left(L_{h}\right), E\left(S_{L_{h}}\right)$ and $\operatorname{Var}\left(S_{L_{h}}\right)$ when $L_{h}$ is the trailing stops strategy for the long position. To compute the correlation, $\operatorname{Corr}\left(N_{h}, S_{N_{h}}\right)$, we use the results of the last section.

For a given $s>0$, we can solve $\phi(\theta)=\mathrm{e}^{s}$, and obtain two solutions for $\theta$,

$$
\begin{aligned}
\mathrm{e}^{\theta_{1}} & =\frac{\mathrm{e}^{s}-\sqrt{ } \mathrm{e}^{2 s}-4 p(1-p)}{2 p}, \\
\mathrm{e}^{\theta_{2}} & =\frac{\mathrm{e}^{s}+\sqrt{ } \mathrm{e}^{2 s}-4 p(1-p)}{2 p} .
\end{aligned}
$$

Note that $\theta_{1}^{\prime}+\theta_{2}^{\prime}=0$. When $p<1 / 2$, we see that $\theta_{1} \rightarrow 0$ and $\theta_{2} \rightarrow \theta^{*}=\ln (q / p)$. The Laplace transform is obtained from theorem 2.6:

$$
E\left(\mathrm{e}^{s N_{h}}\right)=\frac{\mathrm{e}^{\theta_{2}}-\mathrm{e}^{\theta_{1}}}{\left(1-\mathrm{e}^{\theta_{1}}\right) \mathrm{e}^{\theta_{2}(h+1)}-\left(1-\mathrm{e}^{\theta_{2}}\right) \mathrm{e}^{\theta_{1}(h+1)}}, \quad s>0 .
$$

The Laplace transform completely characterizes the probability distribution of the duration $N_{h}$. In principle, the probability distribution can be obtained by the standard inversion theory of Laplace transforms. 
The moments of the trading strategy can be obtained via differentiation. For instance,

$$
E\left(N_{h}\right)=-\left.\frac{\mathrm{d}}{\mathrm{d} s} E\left(\mathrm{e}^{s N_{h}}\right)\right|_{s=0} .
$$

Higher moments are obtained similarly by taking higherorder derivatives of the Laplace transform and then inserting $s=0$. After omitting the simple (but a substantial amount of) algebra, the following moments of the trading strategy can be deduced from the above Laplace transform:

$$
\begin{aligned}
E\left(N_{h}\right) & \frac{h}{p-q}+\frac{q}{(p-q)^{2}}\left\{(q / p)^{h}-1\right\}, \quad p / \frac{1}{2}, \\
E\left(N_{h}\right) & h(h+1), \quad p \quad \frac{1}{2}, \\
\operatorname{Var}\left(N_{h}\right) & \frac{4 p(1-p)}{(2 p-1)^{3}}\left\{h+\frac{1-((1-p) / p)^{h}}{1-(p /(1-p))}\right\}+\frac{4 p h((1-p) / p)^{h+1}}{(2 p-1)^{3}} \\
& +\frac{p(1-p)\left\{((1-p) / p)^{h+1}+3\right\}\left\{((1-p) / p)^{h}-1\right.}{(2 p-1)^{4}}, \\
& p<\frac{1}{2}, \\
\operatorname{Var}\left(N z_{h}\right) & \frac{h(h+1)}{3}\left(2 h^{2}+2 h-1\right), \quad p \rightarrow \frac{1}{2}
\end{aligned}
$$

By Wald's equation, we see that

$$
\begin{aligned}
& E\left(S_{N_{h}}\right) \quad E\left(Y_{1}\right) E\left(N_{h}\right) \\
& h \frac{1 \quad p}{2 p \quad 1}\left\{1 \quad\left(\left(\begin{array}{ll}
1 & p
\end{array}\right) / p\right)^{h}\right\}, \quad p / \frac{1}{2}, \\
& E\left(S_{N_{h}}\right) \quad 0, \quad p \quad \frac{1}{2}, \\
& \left.\left.\operatorname{Var}\left(S_{N_{h}}\right) \quad \frac{1}{2 p} \quad 1\right\}\left\{\begin{array}{lll}
((1) & p
\end{array}\right) / p\right)^{h}
\end{aligned}
$$

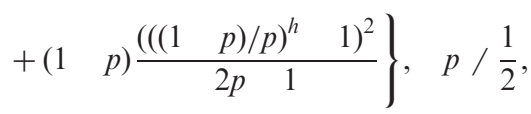

$$
\begin{aligned}
& \operatorname{Var}\left(S_{N_{h}}\right) \quad h(h+1) \quad E\left(N_{h}\right), \quad p \quad \frac{1}{2}, \\
& \operatorname{Corr}\left(N_{h}, S_{N_{h}}\right) \quad \frac{\operatorname{Var}\left(S_{N_{h}}\right) \quad E\left(N_{h}\right) \operatorname{Var}\left(Y_{1}\right)+\left(E\left(Y_{1}\right)\right)^{2} \operatorname{Var}\left(N_{h}\right)}{2 E\left(Y_{1}\right) \sqrt{ } \operatorname{Var}\left(N_{h}\right) \operatorname{Var}\left(S_{N_{h}}\right)}, \\
& \operatorname{Corr}\left(N_{h}, S_{N_{h}}\right) \quad \frac{(2 h+1)}{\sqrt{ } 3 \sqrt{2} h(h+1) \quad 1}, \quad p \rightarrow \frac{1}{2} .
\end{aligned}
$$

The last expression shows that the correlation between $N_{h}$ and $S_{N_{h}}$ is negative when $E\left(Y_{1}\right)=0$, indicating that the longer the short position remains open, the lower the log price is going to be at the stopping time. In a short position, the lower $S_{N_{h}}$ is, the less the loss will be. The correlation of $N_{h}$ with $S_{N_{h}}$, as a function of the expected duration, $E\left(N_{h}\right)$, is shown in figure 1 on a semilogarithmic scale. The vertical scale shows only four decimal place accuracy.

The curve going through the circled data points, $\left(E\left(N_{h}\right), \operatorname{Var}\left(N_{h}\right)\right)$, of figure 2 shows that the variance
$\operatorname{Var}\left(N_{h}\right)$ seems to have a parabolic relationship with $E\left(N_{h}\right)$ regardless of the choice of $p$.

This turns out not to be totally correct. More appropriately, when $p$ is near $1 / 2$, there is indeed a parabolic relationship, namely

$$
\operatorname{Var}\left(N_{h}\right)=\frac{1}{3}\left(2\left(E\left(N_{h}\right)\right)^{2}-E\left(N_{h}\right)\right), \quad p \rightarrow \frac{1}{2} .
$$

However, for $p$ in the neighbourhood of zero, there is another parabolic relationship between $\operatorname{Var}\left(N_{h}\right)$ and $E\left(N_{h}\right)$,

$$
\begin{gathered}
\operatorname{Var}\left(N_{h}\right)=\left(E\left(N_{h}\right)\right)^{2}+E\left(N_{h}\right)\{1-2 h\}-3 h(h+1), \\
p \rightarrow 0^{+} .
\end{gathered}
$$

As the figure suggests, for local regions of $p \in(0,1 / 2)$, a good parabolic relationship may be found between $E\left(N_{h}\right)$ and $\operatorname{Var}\left(N_{h}\right)$. The header of each figure gives the best parabolic fit for that region of $p$.

Example 3.2 (trinomial model): Consider the trinomial model where the $\log$ return, $Y_{1}$, can take three possible values, $-1,1,0$, with respective probabilities $q, p, 1-p-q$. The trinomial model was studied by Boyle (1986) in the context of option valuation. He used the model to price both European and American options. The trailing stops strategy can also be analysed analytically for the trinomial model. For a given $s>0$, we may solve $\phi(\theta)=\mathrm{e}^{s}$, and obtain two solutions for $\theta$ :

$$
\begin{aligned}
\mathrm{e}^{\theta_{1}} & =\frac{\left(\mathrm{e}^{s}+p+q-1\right)-\sqrt{ }\left(\mathrm{e}^{s}+p+q-1\right)^{2}-4 p q}{2 p} \\
\mathrm{e}^{\theta_{2}} & =\frac{\left(\mathrm{e}^{s}+p+q-1\right)+\sqrt{ }\left(\mathrm{e}^{s}+p+q-1\right)^{2}-4 p q}{2 p} .
\end{aligned}
$$

Note that $\theta_{1}^{\prime}+\theta_{2}^{\prime}=0$. When $p<q$, we see that $\theta_{1} \rightarrow 0$ and $\theta_{2} \rightarrow \theta^{*}=\ln (q / p)$. Since both $K(\theta)=p$ and $R(\theta)=q$ are constant functions, and $Y$ is an integer valued random variable, theorem 2.6 gives

$$
\begin{aligned}
E\left(\mathrm{e}^{s N_{h}}\right)= & \frac{\mathrm{e}^{\theta_{2}}-\mathrm{e}^{\theta_{1}}}{\left(1-\mathrm{e}^{\theta_{1}}\right) \mathrm{e}^{\theta_{2}(h+1)}-\left(1-\mathrm{e}^{\theta_{2}}\right) \mathrm{e}^{\theta_{1}(h+1)}, \quad s>0,}, \\
E\left(N_{h}\right)= & \frac{h}{p-q}-\frac{q}{(p-q)^{2}}\left\{1-(q / p)^{h}\right\}, \quad p \neq q, \\
E\left(N_{h}\right)= & \frac{h(h+1)}{2 p}, \quad p=q, \\
\operatorname{Var}\left(N_{h}\right)= & \frac{p(1-p)+q(1-q)+2 p q}{(p-q)^{3}}\left\{h+\frac{1-(q / p)^{h}}{1-(p / q)}\right\} \\
& +\frac{p q\left\{(q / p)^{h+1}+3\right\}\left\{(q / p)^{h}-1\right\}}{(p-q)^{4}} \\
& +\frac{4 p h(q / p)^{h+1}}{(p-q)^{3}}, \quad p<q, \\
\operatorname{Var}\left(N_{h}\right)= & \frac{h(h+1)(h(h+1)+1-3 p)}{6 p^{2}}, \quad p=q .
\end{aligned}
$$



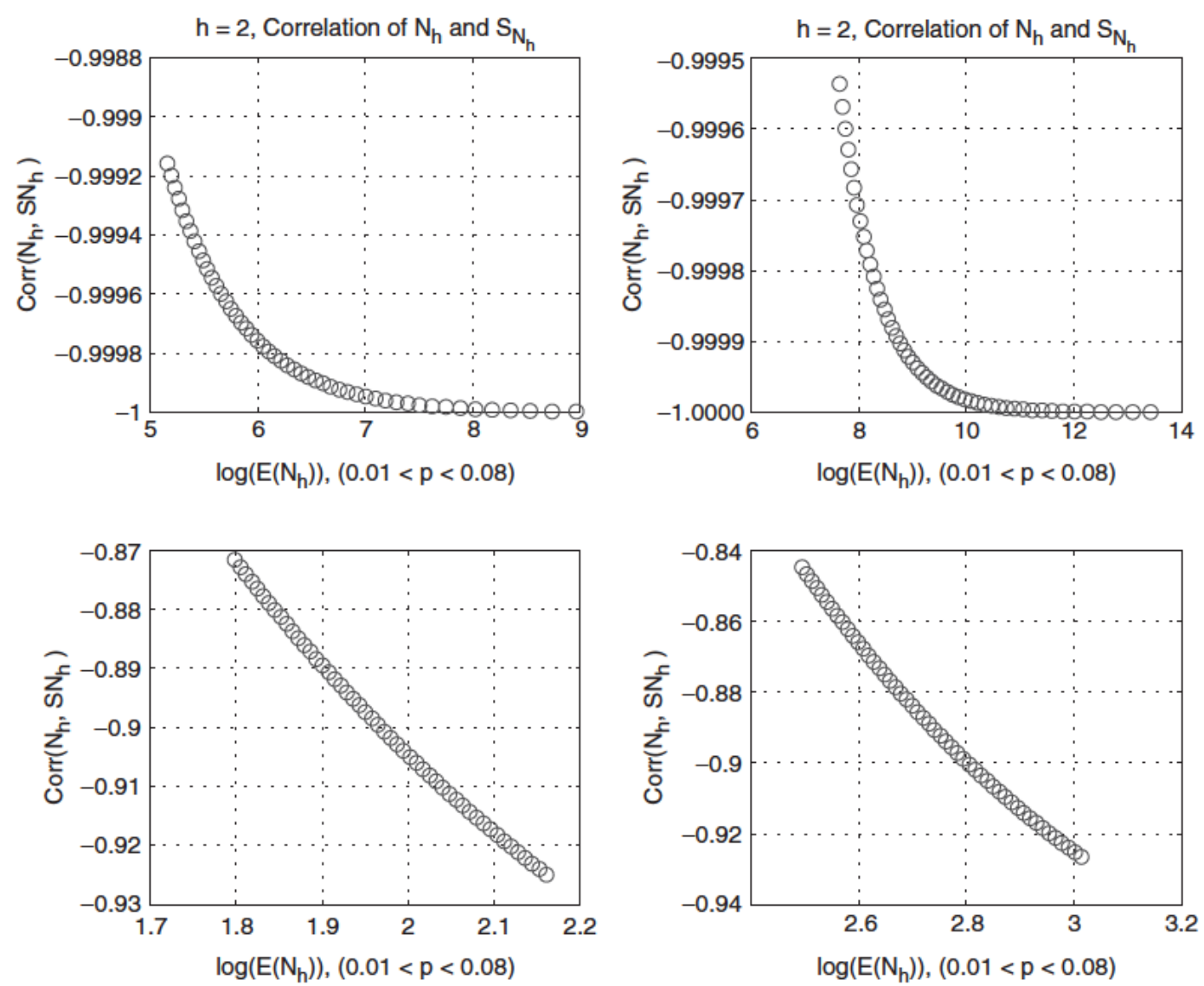

Figure 1. Correlation of trailing stop, binomial model.
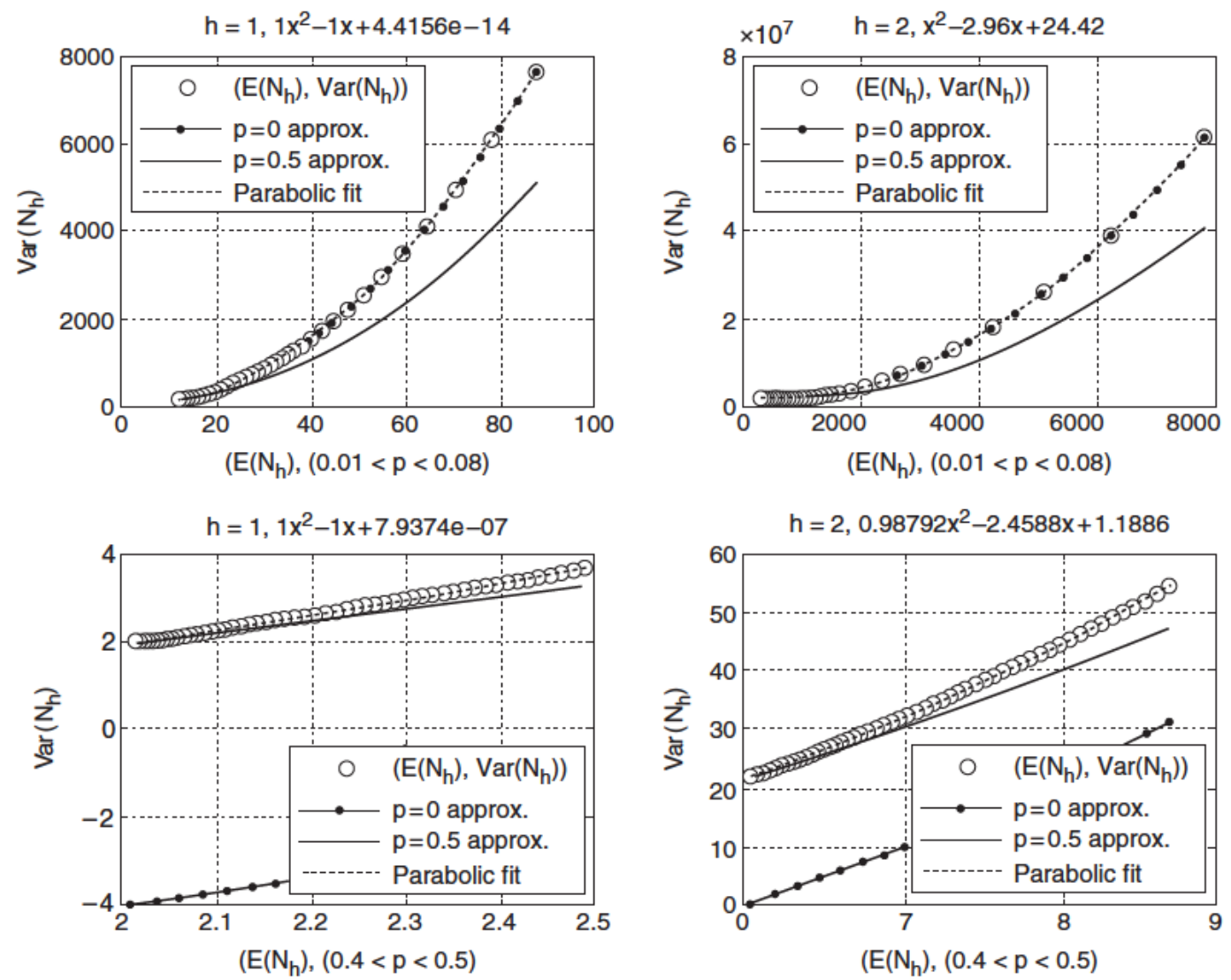

Figure 2. Mean variance curve for trailing stop, binomial model. 
In this example, $\operatorname{Var}\left(S_{N_{h}}\right)$ also follows from a simple modification of the argument of Glynn and Iglehart (1995). By Wald's identity, we see that

$$
\begin{aligned}
& E\left(S_{N_{h}}\right) \quad E\left(Y_{1}\right) E\left(N_{h}\right) \quad h \quad \frac{q}{(p \quad q)}\left\{1 \quad(q / p)^{h}\right\}, \quad p / q, \\
& E\left(S_{N_{h}}\right) \quad 0, \quad p \quad q \\
& \operatorname{Var}\left(S_{N_{h}}\right) \quad \frac{1 A}{A^{2}}, \quad A \frac{q p}{q p+q\left((q / p)^{h} 1\right)}, \quad p<q, \\
& \operatorname{Var}\left(S_{N_{h}}\right) \quad h(h+1) \quad 2 p E\left(N_{h}\right), \quad p \quad q, \\
& \operatorname{Corr}\left(N_{h}, S_{N_{h}}\right) \quad \frac{\operatorname{Var}\left(S_{N_{h}}\right) \quad \operatorname{Var}\left(Y_{1}\right) E\left(N_{h}\right)+\left(E\left(Y_{1}\right)\right)^{2} \operatorname{Var}\left(N_{h}\right)}{2 E\left(Y_{1}\right) \sqrt{ } \operatorname{Var}\left(N_{h}\right) \operatorname{Var}\left(S_{N_{h}}\right)}, \\
& p<q
\end{aligned}
$$$$
\operatorname{Corr}\left(N_{h}, S_{N_{h}}\right) \quad \frac{(2 h+1)}{\sqrt{ } 6 \sqrt{ } h(h+1)+1} 3 p, \quad p \quad q .
$$

For various choices of $p, q$, figure 3 shows that the variance $\operatorname{Var}\left(N_{h}\right)$ is approximately a parabolic function of $E\left(N_{h}\right)$.

Table 1 compares the simulation results for the trinomial model with their corresponding theoretical values. It should be noted that the simulation was performed over a fixed time duration, [0, 10000$]$. During this time period the trading strategy was implemented sequentially. This way, the sample size of the simulated values of $N_{h}$ cannot be controlled. This feature is reflected in the last column of table 1. Also, the choice of $p=0.06$ and $p=0.12$ was made so that $E\left(Y_{1}\right)=-0.56+0.06=-1 / 2$ and $E\left(Y_{1}\right)=0.12-0.42=-3 / 10$.

The amount of expected gain/loss, when $P_{0}=1$, is presented in table 2 . Note that $E\left(Y_{1}\right)=p-q=-0.04$, which might suggest that a short position could be profitable. However, note that $E\left(\mathrm{e}^{Y_{1}}\right)=1.0399$ and $E\left(\mathrm{e}^{Y_{1}}\right)>\mathrm{e}^{r}$ if and only if $r<0.0391$. Hence, it seems as if the short position trailing stops strategy requires that $E\left(\mathrm{e}^{Y_{1}}\right)<\mathrm{e}^{r}$ to remain profitable, and not just that $E\left(Y_{1}\right)<0$. Needless to say that the corresponding conclusion also goes for the long position of the trailing stops strategy. The various correlations are presented in table 3. This shows that $\operatorname{Corr}\left(N_{h}, S_{N_{h}}\right)<0$ for all $E\left(Y_{1}\right)$ in the neighbourhood of zero.

Example 3.3 (geometric model): Consider the model in which the returns are governed by a two-sided geometric model:

$$
P(Y=k)= \begin{cases}\frac{p_{1} p_{2}}{1-q_{1} q_{2}} q_{1}^{k}, & \text { if } k=0,1,2, \ldots, \\ \frac{p_{1} p_{2}}{1-q_{1} q_{2}} q_{2}{ }^{k}, & \text { if } k=-1,-2, \ldots\end{cases}
$$

We can interpret this model as follows. The increment and decrements in log returns may be considered to be independent geometric random variables, $\xi_{1}, \xi_{2}$, with the net amount being $Y=\xi_{1}-\xi_{2}$. It is obvious that $E Y=\left(p_{2}-p_{1}\right) / p_{1} p_{2}$. It is not difficult to show
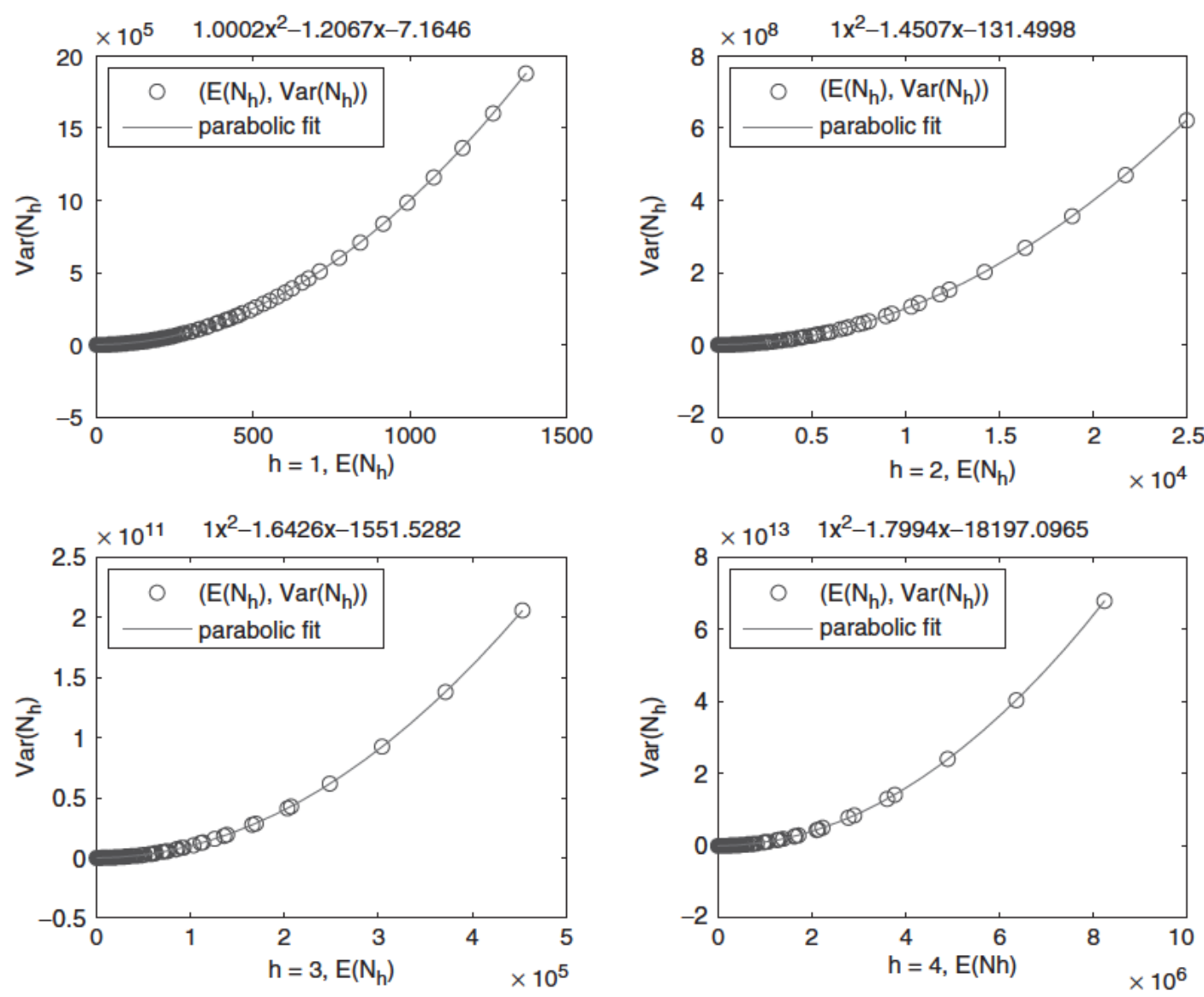

Figure 3. Mean variance curve for trailing stop, trinomial model. 
that exact results for the trailing stops strategy can be obtained. We omit the straightforward details and just report the final results obtained from theorem 2.5. The two roots of the equation, $\phi(\theta)=\mathrm{e}^{s}$, are

$\mathrm{e}^{\theta_{1}}=\frac{1+q_{1} q_{2}-p_{1} p_{2} \mathrm{e}^{s}-\sqrt{\left(1+q_{1} q_{2}-p_{1} p_{2} \mathrm{e}^{s}\right)^{2}-4 q_{1} q_{2}}}{2 q_{1}}$, $\mathrm{e}^{\theta_{2}}=\frac{1+q_{1} q_{2}-p_{1} p_{2} \mathrm{e}^{s}+\sqrt{\left(1+q_{1} q_{2}-p_{1} p_{2} \mathrm{e}^{s}\right)^{2}-4 q_{1} q_{2}}}{2 q_{1}}$.

Note that $\theta_{1}^{\prime}+\theta_{2}^{\prime}=0$. When $q_{1}<q_{2}$ (i.e. $E(Y)<0$ ) and $s \rightarrow 0$, we see that $\theta_{1} \rightarrow 0$ and $\mathrm{e}^{\theta_{2}} \rightarrow q_{2} / q_{1}=: \mathrm{e}^{\theta^{*}}$. Therefore,

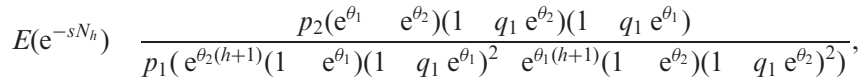

$$
\begin{aligned}
& q_{1}<q_{2},
\end{aligned}
$$

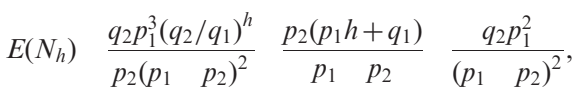

$$
\begin{aligned}
& E(Y) / 0 \text {, } \\
& E\left(N_{h}\right) \frac{p^{2}}{2 q}\left(h^{2}+h\left(1+\frac{4 q}{p}\right)+\frac{2(2 q+p) q}{p^{2}}\right), \\
& \begin{array}{lllll}
p_{1} & p_{2} & p & 1 & q
\end{array}
\end{aligned}
$$

$$
\begin{aligned}
\operatorname{Var}\left(N_{h}\right) & \frac{1}{(E(Y))^{2}}\left\{\operatorname{Var}(Y) E\left(N_{h}\right)+2\left(E(Y) E\left(N_{h}\right) \quad h\right)\right. \\
& \times \frac{q_{2} p_{1}^{2}+q_{1} p_{2}^{2}}{p_{1} p_{2}\left(p_{2} \quad p_{1}\right)}+\left(E(Y) E\left(N_{h}\right) \quad h\right)^{2} . \\
& +\frac{p_{1} q_{2}\left(1+q_{2}\right)\left(p_{2} \quad p_{1}\left(q_{2} / q_{1}\right)^{h}\right)}{p_{2}^{3}\left(p_{1} \quad p_{2}\right)} \\
& \frac{q_{1}\left(1+q_{1}\right)}{p_{1}^{2}} 2 \frac{q_{1}^{2} p_{2}^{4}+q_{2}^{2} p_{1}^{4}\left(q_{2} / q_{1}\right)^{h}}{p_{1}^{2} p_{2}^{3}\left(p_{1} \quad p_{2}\right)} \\
+ & \left.4 h \frac{p_{1}^{2} q_{2}\left(q_{2} / q_{1}\right)^{h}}{p_{2}^{2}\left(p_{2} \quad p_{1}\right)}\right\}, \quad q_{1}<q_{2} .
\end{aligned}
$$

By Wald's equation, applied to the martingales $S_{n}-n$

\begin{tabular}{|c|c|c|c|}
\hline$r$ & $1 \quad E\left(\mathrm{e}^{-r N_{h}}+S_{N_{h}}\right)$ & Std. err. & Sample size \\
\hline 0.05 & 0.0855 & 0.03 & 1168 \\
\hline 0.04 & 0.0193 & 0.03 & 1188 \\
\hline 0.03 & 0.0358 & 0.03 & 1171 \\
\hline 0.02 & 0.1419 & 0.03 & 1219 \\
\hline 0.01 & 0.2549 & 0.03 & 1242 \\
\hline
\end{tabular}
$E\left(Y_{1}\right)$ and $\left(S_{n}-n E\left(Y_{1}\right)\right)^{2}-n \operatorname{Var}\left(Y_{1}\right)$, we obtain

$$
\begin{aligned}
E\left(S_{N_{h}}\right)= & \frac{1}{p_{1} p_{2}}\left\{\frac{q_{2} p_{1}^{3}\left(q_{2} / q_{1}\right)^{h}}{p_{2}\left(p_{2}-p_{1}\right)}+p_{2}\left(p_{1} h+q_{1}\right)-\frac{q_{2} p_{1}^{2}}{p_{2}-p_{1}}\right\}, \\
& q_{1} \neq q_{2} \\
E\left(S_{N_{h}}\right)= & 0, \quad q_{1}=q_{2} \\
\operatorname{Var}\left(S_{N_{h}}\right)= & \frac{p^{2} \operatorname{Var}\left(Y_{1}\right)}{2 q}\left(h^{2}+h\left(1+\frac{4 q}{p}\right)+\frac{2(2 q+p) q}{p^{2}}\right), \\
& p_{1}=p_{2}=p=1-q .
\end{aligned}
$$

\begin{tabular}{|c|c|c|c|c|c|}
\hline$E\left(Y_{1}\right)$ & & Parameters & $h$ & $\operatorname{Corr}\left(N_{h}, S_{N_{h}}\right)$ & Sample size \\
\hline 0.1 & $p$ & $0.3, q \quad 0.2$ & 1 & 0.77 & 5987 \\
\hline 0.0 & $p$ & $0.25, q \quad 0.25$ & 1 & 0.81 & 5028 \\
\hline 0.1 & $p$ & $0.2, q \quad 0.3$ & 1 & 0.87 & 4100 \\
\hline 0.1 & $p$ & $0.3, q \quad 0.2$ & 2 & 0.71 & 2332 \\
\hline 0.0 & $p$ & $0.25, q \quad 0.25$ & 2 & 0.81 & 1641 \\
\hline 0.1 & $p$ & $0.2, q \quad 0.3$ & 2 & 0.89 & 1105 \\
\hline
\end{tabular}

Figure 4 shows that $\operatorname{Var}\left(N_{h}\right)$ can again be approximated by a parabolic function of $E\left(N_{h}\right)$.

Table 1. Comparison of the simulation results for the trinomial model and the corresponding theoretical values.

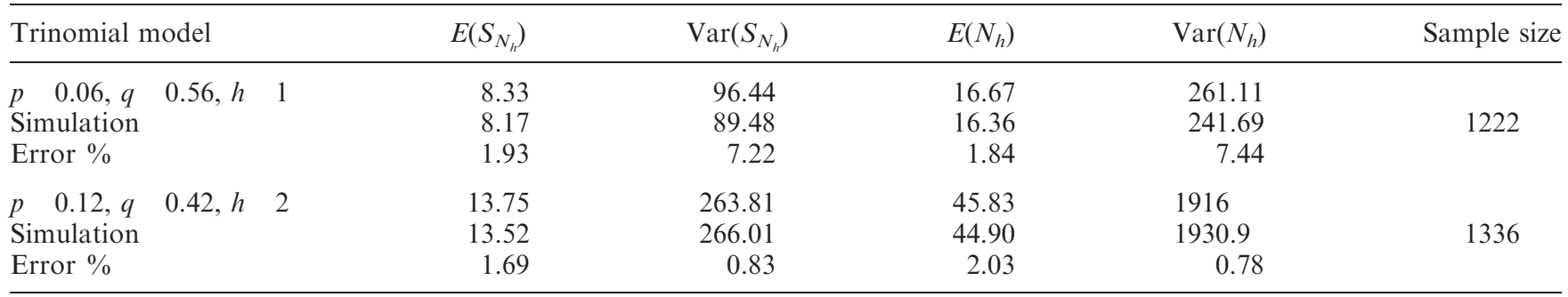

Table 2. Amount of expected gain/loss when $P_{0} \quad 1$ for the trinomial model $\left(\begin{array}{llll}p & 0.06, q & 0.10, h & 1\end{array}\right)$.

Table 3. The various correlations for the trinomial model. 
Table 4 provides simulation results for the geometric model. The amount of expected gain/loss, when $P_{0}=1$, is presented in table 5 . Note that $E\left(Y_{1}\right)=-0.09$, which might suggest that a short position might be profitable. However, note that $E\left(\mathrm{e}^{Y_{1}}\right)=2.86$ and $E\left(\mathrm{e}^{Y_{1}}\right)>\mathrm{e}^{r}$ for all reasonable values of $r \geq 0$. Hence, the short position will always be a losing proposition. The various correlations are presented in table 6 . This shows that
$\operatorname{Corr}\left(N_{h}, S_{N_{h}}\right)<0$ for all $E\left(Y_{1}\right)$ in the neighbourhood of zero.

Example 3.4 (double exponential model): In this model we assume that the log returns follow a (not necessarily symmetric) double exponential model. More precisely, let the upward movement of the log return be governed by $U \sim \operatorname{Exp}(\mu)$ and let the downward movement be
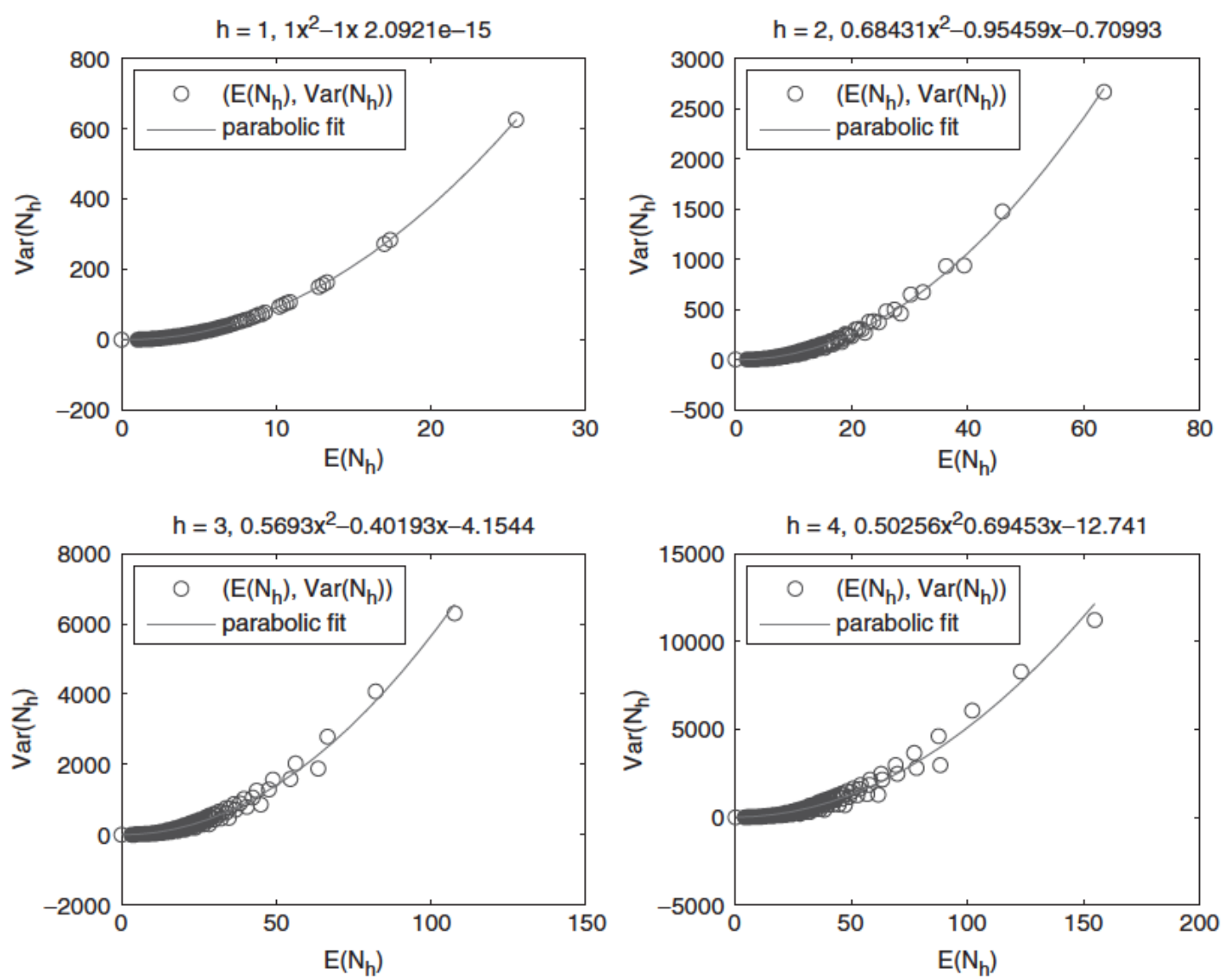

Figure 4. Mean variance curve for trailing stop, geometric model.

Table 4. Simulation results for the geometric model.

\begin{tabular}{|c|c|c|c|c|c|}
\hline Geometric model & $E\left(S_{N_{h}}\right)$ & $\operatorname{Var}\left(S_{N_{h}}\right)$ & $E\left(N_{h}\right)$ & $\operatorname{Var}\left(N_{h}\right)$ & Sample size \\
\hline$p_{1} \quad 1 / 2, p_{2} \begin{array}{c}4 / 9, h \quad 1 \\
\text { Simulation } \\
\text { Error } \%\end{array}$ & $\begin{array}{l}0.81 \\
0.88 \\
7.79\end{array}$ & 20.38 & $\begin{array}{l}3.25 \\
3.29 \\
1.38\end{array}$ & $\begin{array}{l}7.31 \\
7.81 \\
6.84\end{array}$ & 6069 \\
\hline $\begin{array}{lll}p_{1} \quad 1 / 2, p_{2} & 4 / 9, h \quad 2 \\
& \text { Simulation } \\
& \text { Error \% }\end{array}$ & $\begin{array}{l}1.375 \\
1.42 \\
3.21\end{array}$ & 34.68 & $\begin{array}{l}5.5 \\
5.53 \\
0.67\end{array}$ & $\begin{array}{r}22.75 \\
21.06 \\
7.43\end{array}$ & 3612 \\
\hline
\end{tabular}

Table 5. Amount of expected gain/loss when $P_{0} \quad 1$ for the geometric model $\left(\begin{array}{llll}p_{1} & 0.7, p_{2} & 0.66, h & 1\end{array}\right)$.

\begin{tabular}{|c|c|c|c|}
\hline$r$ & $1 E\left(\mathrm{e}^{-r N_{h}}+S_{N_{h}}\right)$ & Std. err. & Sample size \\
\hline 0.04 & 2.93 & 0.32 & 4366 \\
\hline 0.03 & 2.84 & 0.23 & 4382 \\
\hline 0.02 & 4.22 & 0.98 & 4389 \\
\hline 0.01 & 6.09 & 2.01 & 4419 \\
\hline
\end{tabular}


governed by an independent $V \sim \operatorname{Exp}(\lambda)$. The net effect is $Y=U-V$, the density of which is

$$
f_{Y}(y)= \begin{cases}\frac{\lambda \mu}{\lambda+\mu} \mathrm{e}^{\mu y}, & \text { if } y \geq 0, \\ \frac{\lambda \mu}{\lambda+\mu} \mathrm{e}^{\lambda y}, & \text { if } y<0 .\end{cases}
$$

As pointed out in the financial literature (Campbell et al. 1997, Tsay 2002), the log returns tend to have heavier tails than the tails of the corresponding normal density, which is the feature of this model. Once again, our theoretical approach can be employed to obtain closed-form expressions for the Laplace transform of $N_{h}$ along with its mean and variance. We once again omit the details and just list the results. The roots of $\phi(\theta)=\mathrm{e}^{s}$ are

$$
\begin{aligned}
& \theta_{1}=\frac{(\mu-\lambda)-\sqrt{(\lambda+\mu)^{2}-4 \lambda \mu \mathrm{e}^{s}}}{2}, \\
& \theta_{2}=\frac{(\mu-\lambda)+\sqrt{(\lambda+\mu)^{2}-4 \lambda \mu \mathrm{e}^{s}}}{2} .
\end{aligned}
$$

Note that $\theta_{1}^{\prime}+\theta_{2}^{\prime}=0$. When $\lambda<\mu$ (i.e. $E(Y)<0$ ), as $s \rightarrow 0$, we see that $\theta_{1} \rightarrow 0$ and $\theta_{2} \rightarrow \theta^{*}=\mu-\lambda$. We have the following expressions for the mean, variance and Laplace transforms of $N_{h}$ :

$$
\begin{aligned}
E\left(\mathrm{e}^{-s N_{h}}\right) & \frac{\lambda\left(\theta_{2}-\theta_{1}\right)\left(\mu-\theta_{1}\right)\left(\mu-\theta_{2}\right)}{\mu\left\{\theta_{2} \mathrm{e}^{\theta_{1} h}\left(\lambda+\theta_{1}\right)\left(\mu-\theta_{2}\right)-\theta_{1} \mathrm{e}^{\theta_{2} h}\left(\lambda+\theta_{2}\right)\left(\mu-\theta_{1}\right)\right\}}, \\
E\left(N_{h}\right) & \frac{\lambda}{\rho-1}\left\{h+\frac{\rho}{\lambda}+\frac{\rho-\mathrm{e}^{\theta^{*} h}}{\lambda \rho(1-\rho)}\right\}, \quad \rho \quad \frac{\lambda}{\mu} / 1, \\
E\left(N_{h}\right) & \frac{(h \mu+2)^{2}}{2}, \quad \rho \quad \frac{\lambda}{\mu} 1, \\
\operatorname{Var}(N) & \frac{1}{(E(Y))^{2}}\{\operatorname{Var}(Y) E(N)+2(E(Y) E(N)-h) \\
& \times \frac{\left(\mu^{2}+\lambda^{2}\right)}{\lambda \mu(\lambda-\mu)} \cdot+(E(Y) E(N)-h)^{2} \\
& +\frac{2 \mu\left(\lambda-\mu \mathrm{e}^{(\mu-\lambda) h}\right)}{\lambda^{3}(\mu-\lambda)}-\frac{2}{\mu^{2}}-2 \frac{\left(-\lambda^{4}+\mu^{4} \mathrm{e}^{(\mu-\lambda) h}\right)}{\lambda^{3} \mu^{2}(\mu-\lambda)} \\
& \left.+4 h \frac{\mu^{2} \mathrm{e}^{(\mu-\lambda) h}}{\lambda^{2}(\lambda-\mu)}\right\}, \quad \lambda<\mu .
\end{aligned}
$$

Using Wald's equation for the martingales $S_{n}-n E\left(Y_{1}\right)$ and $E\left(S_{n}-n E\left(Y_{1}\right)\right)^{2}-n \operatorname{Var}\left(Y_{1}\right)$, we obtain

$$
\begin{aligned}
E\left(S_{N_{h}}\right) & =h+\frac{\rho}{\lambda}+\frac{\rho-\mathrm{e}^{\theta^{*} h}}{\lambda \rho(1-\rho)}, \quad \rho=\frac{\lambda}{\mu} \neq 1, \\
E\left(S_{N_{h}}\right) & =0, \quad \rho=\frac{\lambda}{\mu}=1, \\
\operatorname{Var}\left(S_{N_{h}}\right) & =\frac{(h \mu+2)^{2} \operatorname{Var}\left(Y_{1}\right)}{2}=\frac{(h \mu+2)^{2}}{\mu^{2}}, \quad \rho=\frac{\lambda}{\mu}=1 .
\end{aligned}
$$

This model was studied by Iglehart and Stone (1983) and later by Glynn and Iglehart (1995). By direct computations they obtained $E\left(L_{h}\right)$ and $E\left(S_{L_{h}}\right)$, where $L_{h}$ is the trailing stops strategy in the long position. They also computed $\operatorname{Var}\left(S_{L_{h}}\right)$; however, it seems that their expression may have an error. Figure 5 shows that $\operatorname{Var}\left(N_{h}\right)$ can again be approximated by a parabolic function of $E\left(N_{h}\right)$.

Table 7 provides simulation results for the double exponential model. The amount of expected gain/loss, when $P_{0}=1$, is presented in table 8 . Note that $E\left(Y_{1}\right)=-0.09$, which might suggest that a short position might be profitable. However, note that $E\left(\mathrm{e}^{Y_{1}}\right)=5.5$ and $E\left(\mathrm{e}^{Y_{1}}\right)>\mathrm{e}^{r}$ for all reasonable values of $r \geq 0$. Hence, the short position will always be a losing proposition. The various correlations are presented in table 9. This shows that $\operatorname{Corr}\left(N_{h}, S_{N_{h}}\right)<0$ for all $E\left(Y_{1}\right)$ in the neighbourhood of zero.

Example 3.5 (log normal model): We now consider the case when the log returns are normally distributed. More precisely, let $Y_{1}, Y_{2}, \ldots \sim_{\text {iid }} N\left(\mu, \sigma^{2}\right)$. Then $\phi(t)=\exp \left(\mu t+(1 / 2) \sigma^{2} t^{2}\right)$, and $\phi(t)=\mathrm{e}^{s}(s>0)$ has two solutions,

$$
\theta_{1}=\frac{-\mu-\sqrt{ } \mu^{2}+2 \sigma^{2} s}{\sigma^{2}}, \quad \theta_{2}=\frac{-\mu+\sqrt{ } \mu^{2}+2 \sigma^{2} s}{\sigma^{2}}
$$

Once again, note that $\theta_{1}+\theta_{2}$ is a constant making $\theta_{1}^{\prime}+\theta_{2}^{\prime}=0$. However, in this case, $Y_{1}$ does not obey the conditions of theorem 2.5. Exact expressions for $E\left(\mathrm{e}^{-s N_{h}}\right)$, $E\left(N_{h}\right)$ and $\operatorname{Var}\left(N_{h}\right)$ for the trailing stops strategy are still unknown. Various approximations are, however, available. For instance (for the case when $\mu \neq 0$ ), Khan and Khan (2004) give

$$
E\left(\mathrm{e}^{s N_{h}}\right) \approx \frac{\delta \mathrm{e}^{\gamma h}}{\gamma \cosh (\delta h)+\gamma \sinh (\delta h)},
$$

Table 6. The various correlations for the geometric model.

\begin{tabular}{ccccccc}
\hline$E\left(Y_{1}\right)$ & \multicolumn{2}{c}{ Parameters } & $h$ & $\operatorname{Corr}\left(N_{h}, S_{N_{h}}\right)$ & Sample size \\
\hline 0.83 & $p_{1}$ & $0.3, p_{2}$ & 0.4 & 1 & 0.54 & 9635 \\
0.00 & $p_{1}$ & $0.4, p_{2}$ & 0.4 & 1 & 0.72 & 7453 \\
0.83 & $p_{1}$ & $0.4, p_{2}$ & 0.3 & 1 & 0.80 & 6226 \\
0.83 & $p_{1}$ & $0.3, p_{2}$ & 0.4 & 2 & 0.57 & 7229 \\
0.00 & $p_{1}$ & $0.4, p_{2}$ & 0.4 & 2 & 0.74 & 4897 \\
0.83 & $p_{1}$ & $0.4, p_{2}$ & 0.3 & 2 & 0.83 & 4023 \\
\hline
\end{tabular}



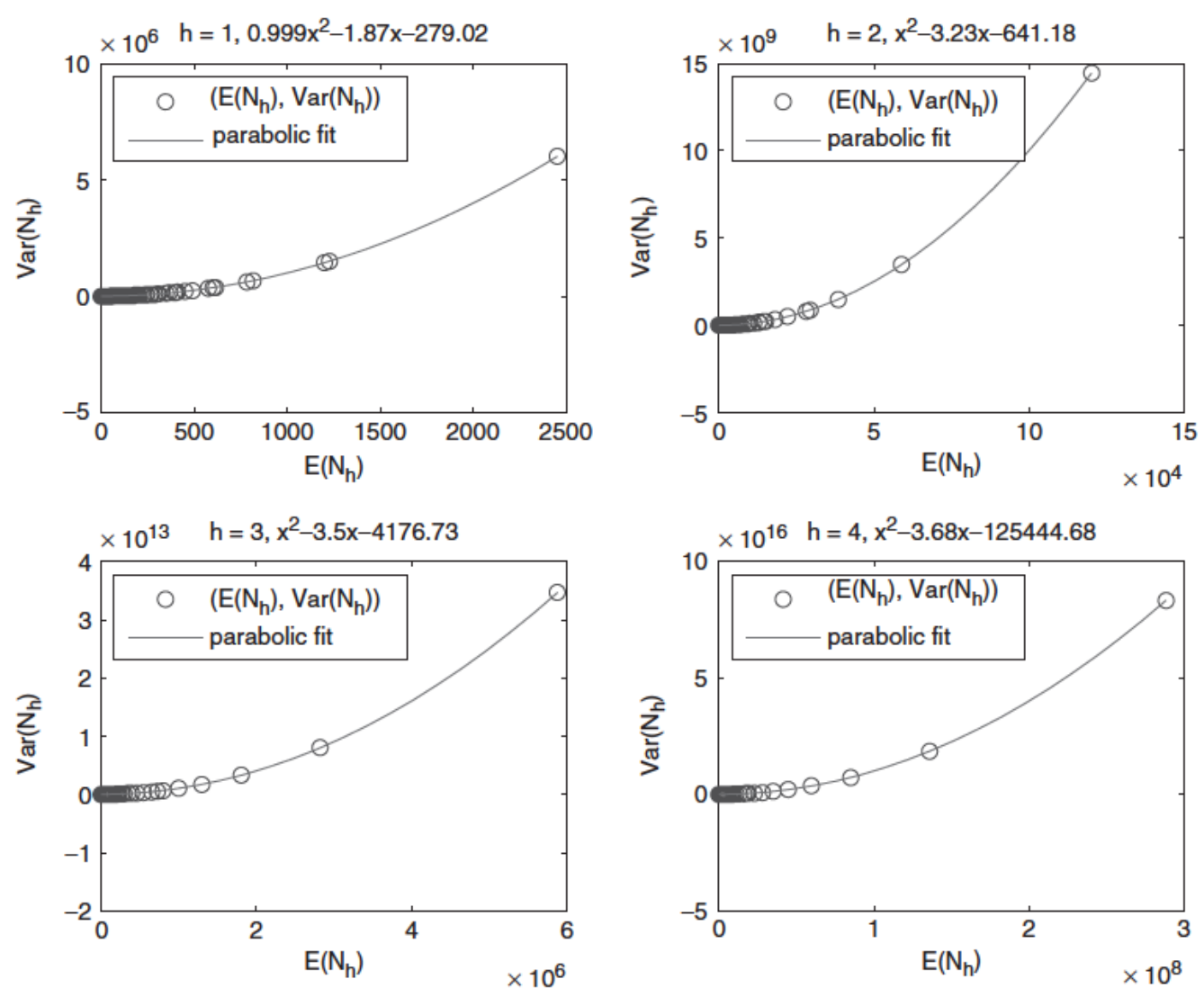

Figure 5. Mean variance curve for trailing stop, double exponential model.

Table 7. Simulation results for the double exponential model.

\begin{tabular}{|c|c|c|c|c|c|}
\hline Exponential model & $E\left(S_{N_{h}}\right)$ & $\operatorname{Var}\left(S_{N_{h}}\right)$ & $E\left(N_{h}\right)$ & $\operatorname{Var}\left(N_{h}\right)$ & Sample size \\
\hline $\begin{array}{l}\mu \quad 1.2, \lambda \quad 1.0, h \quad 2 \\
\text { Simulation } \\
\text { Error \% }\end{array}$ & $\begin{array}{r}1.91 \\
2.12 \\
11.01\end{array}$ & 33.95 & $\begin{array}{r}11.45 \\
11.60 \\
1.37\end{array}$ & $\begin{array}{r}100.35 \\
105.23 \\
4.86\end{array}$ & 1723 \\
\hline $\begin{array}{l}\mu \quad 1.1, \lambda \quad 1.0, h \quad 3 \\
\text { Simulation } \\
\text { Error \% }\end{array}$ & $\begin{array}{r}1.42 \\
1.62 \\
13.95\end{array}$ & 43.97 & $\begin{array}{r}15.67 \\
16.07 \\
2.58\end{array}$ & $\begin{array}{r}181.84 \\
199.29 \\
9.59\end{array}$ & 1244 \\
\hline
\end{tabular}

Table 8. Amount of expected gain/loss when $P_{0} \quad 1$ for the double exponential model $\left(\begin{array}{llll}\mu & 1.1, \lambda & 1.0, h & 1\end{array}\right)$.

\begin{tabular}{|c|c|c|c|}
\hline$r$ & $1 E\left(\mathrm{e}^{-r N_{h}}+S_{N_{h}}\right)$ & Std. err. & Sample size \\
\hline 0.04 & 6.12 & 0.96 & 3847 \\
\hline 0.03 & 4.28 & 0.41 & 3912 \\
\hline 0.02 & 5.65 & 0.64 & 3901 \\
\hline 0.01 & 5.76 & 0.78 & 3885 \\
\hline
\end{tabular}

Table 9. The various correlations for the double exponential model.

\begin{tabular}{|c|c|c|c|c|c|c|}
\hline \multirow{2}{*}{$\frac{E\left(Y_{1}\right)}{1 / 11}$} & \multicolumn{3}{|c|}{ Parameters } & \multirow{2}{*}{$\frac{h}{1}$} & \multirow{2}{*}{$\frac{\operatorname{Corr}\left(N_{h}, S_{N_{h}}\right)}{0.77}$} & \multirow{2}{*}{$\frac{\text { Sample size }}{3047}$} \\
\hline & $\mu$ & $1.1, \lambda$ & 1.0 & & & \\
\hline 0.0 & $\mu$ & $1.0, \lambda$ & 1.0 & 1 & 0.73 & 4484 \\
\hline $1 / 11$ & $\mu$ & $1.0, \lambda$ & 1.1 & 1 & 0.71 & 4682 \\
\hline $1 / 11$ & $\mu$ & $1.1, \lambda$ & 1.0 & 2 & 0.81 & 2091 \\
\hline 0.0 & $\mu$ & $1.0, \lambda$ & 1.0 & 2 & 0.79 & 2498 \\
\hline $1 / 11$ & $\mu$ & $1.0, \lambda$ & 1.1 & 2 & 0.72 & 2703 \\
\hline
\end{tabular}


Table 10. Simulation results for the log normal model.

\begin{tabular}{|c|c|c|c|c|c|c|c|c|}
\hline \multicolumn{4}{|c|}{ Normal model } & \multirow{2}{*}{$\begin{array}{r}E\left(S_{N_{h}}\right) \\
0.02\end{array}$} & \multirow{2}{*}{$\begin{array}{r}\operatorname{Var}\left(S_{N_{h}}\right) \\
2.41\end{array}$} & \multirow{2}{*}{$\frac{E\left(N_{h}\right)}{9.97}$} & \multirow{2}{*}{$\frac{\operatorname{Var}\left(N_{h}\right)}{68.81}$} & \multirow{2}{*}{$\frac{\text { Sample size }}{2006}$} \\
\hline$\mu$ & $0, \sigma$ & $0.5, h \quad 1$ & & & & & & \\
\hline$\mu$ & $0, \sigma$ & $1.0, h \quad 1$ & & 0.06 & 4.73 & 4.63 & 14.62 & 4318 \\
\hline$\mu$ & $0, \sigma$ & $2.0, h \quad 1$ & & 0.08 & 12.09 & 3.02 & 5.75 & 6624 \\
\hline$\mu$ & 0.1 , & $\sigma \quad 0.5, h$ & 1 & 1.64 & 9.86 & 15.96 & 200.03 & 1253 \\
\hline$\mu$ & 0.1 , & $\sigma \quad 1.0, h$ & 1 & 0.50 & 7.06 & 5.48 & 21.18 & 3647 \\
\hline$\mu$ & 0.1 , & $\sigma \quad 2.0, h$ & 1 & 0.34 & 14.43 & 3.24 & 6.80 & 6167 \\
\hline$\mu$ & $0, \sigma$ & $0.5, h \quad 2$ & & 0.14 & 6.02 & 25.63 & 425.12 & 780 \\
\hline$\mu$ & $0, \sigma$ & $1.0, h \quad 2$ & & 0.09 & 9.38 & 9.80 & 68.20 & 2040 \\
\hline$\mu$ & $0, \sigma$ & $2.0, h \quad 2$ & & 0.07 & 19.79 & 4.82 & 16.15 & 4144 \\
\hline$\mu$ & 0.1 , & $\sigma \quad 0.5, h$ & 2 & 5.73 & 64.83 & 57.93 & 2514.91 & 345 \\
\hline$\mu$ & 0.1 , & $\sigma \quad 1.0, h$ & 2 & 1.27 & 20.48 & 12.64 & 119.61 & 1577 \\
\hline$\mu$ & 0.1 , & $\sigma \quad 2.0, h$ & 2 & 0.65 & 24.66 & 5.21 & 19.57 & 3836 \\
\hline
\end{tabular}

Table 11. Amount of expected gain/loss when $P_{0} \quad 1$ for the $\log$ normal model $\left(\begin{array}{llll}\mu & 0.485, \sigma & 1.0, h & 1\end{array}\right)$.

\begin{tabular}{|c|c|c|c|}
\hline$r$ & $1 E\left(\mathrm{e}^{-r N_{h}}+S_{N_{h}}\right)$ & Std. err. & Sample size \\
\hline 0.04 & 0.08 & 0.03 & 3685 \\
\hline 0.03 & 0.05 & 0.03 & 3729 \\
\hline 0.02 & 0.003 & 0.04 & 3664 \\
\hline 0.01 & 0.03 & 0.04 & 3735 \\
\hline
\end{tabular}

Table 12. The various correlations for the log normal model.

\begin{tabular}{cccccc}
\hline Parameters & $h$ & $\operatorname{Corr}\left(N_{h}, S_{N_{h}}\right)$ & Sample size \\
\hline$\mu$ & $0.1, \sigma$ & 1.0 & 1 & 0.83 & 3604 \\
$\mu$ & $0.0, \sigma$ & 1.0 & 1 & 0.79 & 4318 \\
$\mu$ & $0.1, \sigma$ & 1.0 & 1 & 0.75 & 4908 \\
$\mu$ & $0.1, \sigma$ & 1.0 & 2 & 0.86 & 1578 \\
$\mu$ & $0.0, \sigma$ & 1.0 & 2 & 0.81 & 1990 \\
$\mu$ & $0.1, \sigma$ & 1.0 & 2 & 0.75 & 2469 \\
\hline
\end{tabular}

where $\gamma=-\mu / \sigma^{2}$ and $\delta=\left[\gamma^{2}+\left(2 s / \sigma^{2}\right)\right]^{1 / 2}$. When $\mu=0$, we have

$$
E\left(\mathrm{e}^{s N_{h}}\right) \approx \frac{1}{\cosh \left(h\left(2 s / \sigma^{2}\right)^{1 / 2}\right)} .
$$

This Laplace transform turns out to be the exact Laplace transform of

$$
T:=\inf \left\{t \geq 0: W(t)-\min _{0 \leq s \leq t} W(s) \geq h\right\},
$$

where $W(t)$ is the Wiener process with drift parameter $\mu$ and volatility parameter $\sigma$. The question concerning the quality of the approximation of $E\left(N_{h}\right)$ has been discussed by several authors (Dobben de Bruy 1968, Reynolds 1975, Khan 1978). Khan (1978) also provides refined approximations, and empirical evidence concerning the quality of such approximations is given in example 3 (pp. 74-75) for normal and exponential distributions. Table 10 gives the simulation results for this model.

The amount of expected gain/loss, when $P_{0}=1$, is presented in table 11 . Note that $E\left(Y_{1}\right)=-0.485$, which might suggest that a short position might be profitable. However, note that $E\left(\mathrm{e}^{Y_{1}}\right)=\mathrm{e}^{0.015}$ and $E\left(\mathrm{e}^{Y_{1}}\right)>\mathrm{e}^{r}$ if and only if $r<0.015$. Hence, the short position will be a losing proposition when the risk-free rate is low. The various correlations are presented in table 12. This shows that $\operatorname{Corr}\left(N_{h}, S_{N_{h}}\right)<0$ for all $E\left(Y_{1}\right)$ in the neighbourhood of zero.

\section{Conclusions}

In this section we collect the salient features of this paper.

1. The sign of the correlation between $S_{v}$ and $v$ is always controlled by the factor

$$
\frac{\operatorname{Var}\left(S_{\nu}\right)+\left(E\left(Y_{1}\right)\right)^{2} \operatorname{Var}(v)-\operatorname{Var}\left(Y_{1}\right) E(v)}{E\left(Y_{1}\right)}
$$

for any trading strategy that is adapted to the log returns filtration, $\sigma\left(Y_{1}, \ldots, Y_{n}\right), n \geq 1$. As shown by the binomial and trinomial models, when $E\left(Y_{1}\right)<0$, this amount is negative and rather 
close to negative one for the trading the line strategy, $v=N_{h}$. The same conclusions seem to hold for all the other models studied in this paper. To show that $E\left(S_{N_{h}}\right)$ is a decreasing function of $h$, when $E\left(Y_{1}\right)<0$, consider $v_{2}=N_{h_{2}}$, and $v_{1}=N_{h_{1}}$, when $h_{2}>h_{1}$. Now, $S_{n} \mathrm{z}-n E\left(Y_{1}\right)$, being a martingale,

$$
\begin{aligned}
E\left(S_{v_{2}}-S_{v_{1}} \mid \mathcal{F}_{v_{1}}\right)= & E\left(S_{v_{2}}-S_{v_{1}}-\left(v_{2}-v_{1}\right) E\left(Y_{1}\right) \mid \mathcal{F}_{v_{1}}\right) \\
& \quad+E\left(v_{2}-v_{1} \mid \mathcal{F}_{v_{1}}\right) E\left(Y_{1}\right) \\
\leq 0 &
\end{aligned}
$$

where $\mathcal{F}_{v_{1}}$ is the information up to time $N_{h_{1}}$. The last inequality follows since $v_{2}=N_{h_{2}} \geq N_{h_{1}}=v_{1}$ and $E\left(Y_{1}\right)<0$. The inequality becomes strict if $N_{h_{2}}<N_{h_{1}}$ with positive probability. Hence, $E\left(S_{N_{h}}\right)$ is a nonincreasing function of the triggering constant $h$, whenever $E\left(Y_{1}\right)<0$. However, as the last item (below) explains, this does not necessarily mean that we will gain more with $h_{2}$ versus $h_{1}$, when $E\left(Y_{1}\right)<0$.

2. If $E\left(Y_{1}\right)=0$, i.e. no drift in the log returns, then, for any strategy, $v$, that is independent of the filtration of the $\log$ returns, $\operatorname{Corr}\left(v, S_{v}\right)=0$. However, as the binomial and trinomial examples have shown, this is not so when $v=N_{h}$. For the models we have presented, $\operatorname{Corr}\left(N_{h}, S_{N_{h}}\right)<0$, even when $E\left(Y_{1}\right)=0$. This means that the longer we wait with the trailing stop strategy, $N_{h}$, the more we expect to gain, when $E\left(Y_{1}\right) \leq 0$.

3. Even when $E\left(Y_{1}\right)>0$ and small, the correlation of $N_{h}, S_{N_{h}}$, did not change sign in the examples for which we were able to find a closed-form expression for $\operatorname{Corr}\left(N_{h}, S_{N_{h}}\right)$ and also via simulation for the other examples. Therefore, we may conclude that $\operatorname{Corr}\left(N_{h}, S_{N_{h}}\right)<0$ for all values of $E\left(Y_{1}\right)$ in the neighbourhood of zero (and not just at zero), since the correlation is a continuous function of $E\left(Y_{1}\right)$. When $E\left(Y_{1}\right)>0$, by a similar argument as in (1), we should remark that $E\left(S_{N_{h}}\right)$ becomes a non-decreasing function of $h$.

4. As the examples of the last section suggest, the variance of the duration that the position remains open, $\operatorname{Var}\left(N_{h}\right)$, seems to have a parabolic relationship with the expected duration, $E\left(N_{h}\right)$. The coefficients of the parabola are functions of the trigger size $h$. Furthermore, the larger we pick the triggering constant, $h$, the larger the expected duration and, in turn, the more unstable the strategy becomes.

5. The variance of $S_{N_{h}}$ also seems to have a parabolic relation with $E\left(S_{N_{h}}\right)$. For instance, for both the binomial and trinomial models,

$$
\operatorname{Var}\left(S_{N_{h}}\right)=h-E\left(S_{N_{h}}\right)+\left(E\left(S_{N_{h}}\right)-h\right)^{2} .
$$

Since $E\left(S_{N_{h}}\right)=E\left(Y_{1}\right) E\left(N_{h}\right)$, we also have

$$
\operatorname{Var}\left(S_{N_{h}}\right)=h-E\left(Y_{1}\right) E\left(N_{h}\right)+\left(E\left(Y_{1}\right) E\left(N_{h}\right)-h\right)^{2} .
$$

This indicates that, when $E\left(Y_{1}\right)<0$, one cannot hope to find an optimal $h$ that simultaneously minimizes the expected stopped amount, $E\left(S_{N_{h}}\right)$, and also minimizes the variance, $\operatorname{Var}\left(S_{N_{h}}\right)$.

6. It seems reasonable to propose that the distribution of a constant multiple of $N_{h}$, when $E(Y)<0$, is approximately a geometric random variable, at least when assumptions (A1), (A2), and (A3) hold. This should be compared with the known approximation of $N_{h}$ (Khan 1995, Khan and Khan 2004), which states that $N_{h} \mathrm{e}^{-\theta^{*} h}$ is approximately an exponential random variable, as $h$ becomes large.

7. If the price dynamics are assumed to follow a geometric random walk, even when $E\left(Y_{1}\right)<0$, any trading strategy in the short position, that is independent of the filtration $\sigma\left(Y_{1}, \ldots, Y_{n}\right), n \geq 1$, will give time discounted gains to be negative provided $E\left(\mathrm{e}^{Y_{1}}\right)>\mathrm{e}^{r}$, where $r$ is the continuously compounding discount rate. That is, for those price dynamics in which $E\left(Y_{1}\right)<0$ and $E\left(\mathrm{e}^{Y_{1}}\right)>\mathrm{e}^{r}$, there cannot exist a trading strategy that is independent of the log returns process, and gives positive time discounted gains. In fact, this result remains valid for a wide class of adaptive strategies. A similar observation holds for the long position trading strategies.

8. For the trailing stops strategy, $N_{h}$, adapted to the filtration, $\sigma\left(Y_{1}, \ldots, Y_{n}\right), n \geq 1$, we observe the phenomenon of item (7) in our simulations. In fact, for the geometric model this observation takes even a more acute form. This is due to the fact that, on the one hand, the geometric random variable can take arbitrarily large values and, on the other, the price can never go below zero, regardless of how large in magnitude the negative value of the double sided geometric random variable is. Since, in a short position, by investing $\$ 1$, one cannot hope to gain more than $\$ 1$; however, there is no limit to how much one may lose. Hence, the short position is inherently more risky than the long position. Furthermore, an indicator of a possible gain is the criterion $E\left(\mathrm{e}^{Y_{1}}\right)<\mathrm{e}^{r}$, where $r$ is the riskfree rate, and not just that $E\left(Y_{1}\right)<0$.

\section{Acknowledgements}

We would like to sincerely thank the referees for their several valuable suggestions that improved the paper considerably. The second author's research was partially supported by IMA, University of Minnesota, National Science Foundation grant DMS 9810289.

\section{References}

Acar, E. and Satchell, S., editors, Advanced Trading Rules, 2nd ed., 2002 (Oxford: Woburn, MA).

Billingsley, P., Probability and Measure, 1979 (Wiley: New York). 
Boyle, P., Option valuation using a three jump process. Int. Options J., 1986, 3, 712.

Campbell, J.Y., Lo, A.W. and MacKinlay, A.C., Econometrics of Financial Markets, 1997 (Princeton University Press: Princeton, NJ).

Cofnas, A., Strategies for setting stops. Futures: News Anal. Strat. Futures, Options Deriv. Trad, 2004, 33, 30.

Cox, J.C., Ross, S.A. and Rubinstein, M., Option pricing: a simplified approach. J. finan. Econ., 1979, 7, 229263.

Darling, D.A. and Siegert, A.J.F., The first passage problem for a continuous Markov process. Ann. Math. Stat., 1953, 24, 624639.

Dobben de Bruyn, C.S., Cumulative Sum Tests: Theory and Practice, 1968 (Hafner: New York) (Griffin's Statistical Monographs).

Eng, W.F., Trading Rules II: More Strategies for Success, 1996 (Dearborn Financial: Chicago).

Glynn, P.W. and Iglehart, D.L., Trading securities using trailing stops. Mgmt Sci., 1995, 41, 10961106.

Iglehart, D.L. and Stone, M.L., Regenerative simulation for estimating extreme values. Oper. Res., 1983, 6, 11451166 .

Jenks, P and Eckett, S., editors, The Global investor Book of Investing Rules: Invaluable Advice from 150 Master
Investors, 2002 (Financial Times/Prentice Hall: New York).

Khan, R.A., Wald's SPRT approximations to the average run length in cusum procedures. J. statist. Plann. Infer., 1978, 2, 6377.

Khan, R.A., Some first passage problems related to cusum procedures. Stoch. Proc. Appl., 1979, 9, 207215.

Khan, R.A., On cumulative sum procedures and the SPRT with applications. J. R. statist. Soc. B, 1984, 46, 221231

Khan, R.A., Detecting changes in probabilities of multi component process. Sequent. Anal., 1995, 14, 375388.

Khan, R.A. and Khan, M.K., On the use of the SPRT in determining the properties of some cusum procedures. Sequent. Anal., 2004, 23, 124.

Markese, J., How the right buy and sell orders boost your profits. Money, 1990, 19, 135.

Reynolds, M.R., Approximations to the average run length in cumulative sum control charts. Technometrics, 1975, 17, 6571.

Shen, S. and Wang, A.M., On stop loss strategies for stock investments. Appl. Math. Comput., 2001, 119, 317337.

Tsay, T.S., Analysis of Financial Time Series, 2002 (Wiley: New York). 